\title{
Variability in feeding of Gammarus pulex: moving towards a more standardised feeding assay
}

\author{
Annika Agatz ${ }^{1,2^{*}}$ and Colin D Brown
}

\begin{abstract}
Background: Focusing on feeding as an endpoint in ecotoxicological studies is a useful and sensitive tool to detect sub-lethal impacts on individual organisms with relevance to higher levels of organisation (i.e. population and ecosystem levels). We conducted a series of experiments to identify and quantify the influence of parasite infection and food source, food quality, body size and acclimation time prior to testing on the feeding rate of individual Gammarus pulex. Our aim was to assess the variability in feeding rate associated with these factors to support design of feeding assays with individual organisms at a daily resolution.

Results: Overall, feeding rates varied enormously across experiments, and all factors were confirmed to have a significant impact on feeding rates. Reducing the intra-specific variability by using a particular sub-group within each tested factor (except acclimation time) was found to be indispensable for a successful feeding assay with individual organisms. Focusing on organisms of a sub-group in terms of parasite infection and body mass resulted in a reduction in intra-specific variability of up to $50 \%$ and $57 \%$, respectively. Using a food source of particular quality reduced the variability by up to $38 \%$.

Conclusions: We presented a list of factors that naturally have an impact on feeding rates of Gammarus, quantified their impact on the variability in feeding rates, discussed their importance for consideration when planning a feeding assay and suggested some additional measurements alongside the feeding assay to improve data comparison between studies.
\end{abstract}

Keywords: Parasite infection; Food source; C-N ratio; Toxicity testing

\section{Background}

Focusing on feeding as an endpoint in ecotoxicological studies is a useful and sensitive tool to detect sub-lethal impacts on individual organisms with relevance to higher levels of organisation (i.e. population and ecosystem levels). Energy availability depends on feeding [1,2], and the energy budget can be considered an indicator of the overall condition of an organism [3]. Feeding determines the health of a population because altered growth and reproduction can be instigated by an effect on feeding [4-7]. Furthermore, reduced feeding can, at weak levels, reduce the possibility of survival due to interference with further sub-lethal effects and, at strong levels, cause death. Beyond secondary impacts of effects on feeding at the population level, feeding activity can play

\footnotetext{
* Correspondence: annika.agatz@york.ac.uk

${ }^{1}$ Environment Department, University of York, Heslington, York YO10 5DD, UK

${ }^{2}$ Food and Environment Research Agency, Sand Hutton, York YO 41 1LZ, UK
}

a direct role at the ecosystem level due to its importance for nutrient cycling.

One group of organisms responsible for a high proportion of the nutrient cycling in freshwaters are detritivores like Gammarus due to their key role for litter breakdown through fragmentation of leaf material $[8,9]$. Feeding of gammarids can be affected at low levels of pollution [10-14], impacts are almost instantaneous, and ex situ feeding assays are representative of leaf decomposition in the field [15]. Therefore, ex situ feeding assays are a useful tool to detect impacts with strong relevance to the ecosystem level.

Laboratory feeding assays with gammarids have been conducted for several decades $[10,14,16]$ and follow the method of either time-response feeding experiments [17-20] or mass feeding assays [21,22]. Ecotoxicological studies have been carried out, measuring the composite feeding rate over periods from 4 to 7 days [16], and recovery potential was mostly not included (for exceptions, 
see $[23,24])$. These kinds of studies do not represent the majority of exposures to contaminants in the field. More environmentally realistic exposure regimes (short-term and fluctuating exposures) are scarce amongst communicated studies. In order to test more environmentally realistic exposures, multiple measures for the same test organisms are needed. This means that mass feeding assays are the only suitable method, because changing the food source (as is done in time-response feeding experiments) can alter the feeding rate itself. A reduction of the temporal resolution in feeding assays is likely to improve the representation of exposure in the field, but it is likely to be accompanied by increased variability in results. This arises because both the methodological uncertainty and the relative importance of intra-specific variability between test organisms will increase.

Intra-specific variability is an important influence in ecotoxicology, particularly when studying sub-lethal effects. There may be differences in the endpoint of interest amongst individuals which are so large that it may be more appropriate to focus on a sub-group of the test species in order to detect changes caused by the tested stressor. Thus, reducing the intra-specific variability in the test system will increase the statistical power to detect effects. That is the reason why such tests are mainly conducted with more than one individual per replicate, because intra-specific variability has less impact on the results using this method. The intra-specific variability in feeding rate needs to be quantified to identify which sub-group of Gammarus to use in feeding assays at a daily resolution.

Several natural factors are known to influence the feeding rate of organisms, such as food source, food quality, body size, temperature, reproductive status, parasite infection and water quality. For gammarids, many of these influences have been reported in the past (summarised by Kunz et al. [16]), but the quantitative influence on feeding was either not reported or only given for the food source used in the particular test without further information on the nutritional status of the food source used. Thus, identification of the quantitative impact of natural factors on feeding rate by comparison of control treatments from earlier studies is impossible. We conducted a series of experiments to identify and quantify the influence of parasite infection and food source, food quality, body size and acclimation time on the feeding rate of Gammarus pulex. The aim was to identify a more standardised way to measure the influence of xenobiotics on the individual feeding rate of gammarids at a daily resolution to allow the investigation of effects from short-term and/or fluctuating exposures.

\section{Results and discussion}

For all experiments, the $\mathrm{pH}$ ranged between 7.4 and 7.9; the oxygen content was always higher than $75 \%$ saturation; and the temperature ranged between $12.2^{\circ} \mathrm{C}$ and $14.0^{\circ} \mathrm{C}$. The measured $\mathrm{pH}$ was close to the optimum (7.2 to 7.8 ) for gammarids given by Schellenberg [25]. Oxygen content and temperature of the test medium fulfilled the conditions preferred by G. pulex [26].

\section{General findings}

The overall feeding rate of the first experiment (impact of food source and parasite infection) was $0.21 \pm 0.14 \mathrm{mg}$ $($ food $) /($ mg (gammarid) $\times \mathrm{d}$ ) without distinguishing the influence of food source and parasite infection (Figure 1, column 2). This overall feeding rate ranged between $0.17 \pm 0.13$ and $0.37 \pm 0.20 \mathrm{mg}$ (food) $/(\mathrm{mg}$ (gammarid) $\times$ d) when calculated on a daily basis. A reduction of the variability of the test results by $1.6 \%$ was observed on discarding the first feeding period from the data analysis (Figure 1, columns 1 and 2). Data for the first feeding period $\left(t_{0 \mathrm{~h}}\right.$ to $\left.t_{24 \mathrm{~h}}\right)$ were excluded from further analysis because of a significant difference in feeding rate relative to subsequent periods.

The overall feeding rate in the next experiment (impact of body mass) without distinguishing on body mass was $0.37 \pm 0.28 \mathrm{mg}($ food $) /(\mathrm{mg}$ (gammarid) $\times \mathrm{d})$ (Figure 1 , column 8$)$ and ranged between $0.23 \pm 0.25$ and $0.51 \pm$ $0.54 \mathrm{mg}($ food $) /(\mathrm{mg}$ (gammarid) $\times \mathrm{d})$ when calculated on a daily basis.

Overall, the intra-specific variability in feeding rate was very high. The standard deviations of the measured feeding rates were $66 \%$ and $75 \%$ of the average values for the two experiments described above when no differentiation in the three tested factors (food source, parasite infection and body mass) was made (Figure 1 , columns 1 and 8 ). The large variability indicated a low statistical power in any tests of individual feeding rate of G. pulex at a daily resolution and thus the need for further work to understand and reduce intra-specific variability.

\section{Food source}

The feeding rate of non-infected gammarids was significantly influenced $(p<0.001$, power $=1$, overall difference amongst treatment groups; ANOVA, Holm-Sidak test) by leaf type (Figure 1, columns 3 to 5 ) for experiments where gammarids were fed with different sources of horse chestnut. The food source $\mathrm{nD}$ (not decomposed) gave the lowest feeding rate $(0.07 \pm 0.05 \mathrm{mg}$ (food) $/(\mathrm{mg}$ $($ gammarid $) \times d)$ ), the feeding rate of organisms fed with source DC (decomposed with Cladosporium for 2 weeks) was intermediate $(0.22 \pm 0.09 \mathrm{mg}$ (food)/(mg (gammarid) $\times d)$ )), and food source D (decomposed with Cladosporium for 3 months) resulted in the highest feeding rate $(0.36 \pm 0.10 \mathrm{mg}$ (food) $/(\mathrm{mg}$ (gammarid) $\times$ d))). Dangles and Guerold [27] found the same relationship for the freshwater amphipod Gammarus fossarum, and Graça et al. [28] observed that G. pulex ate 


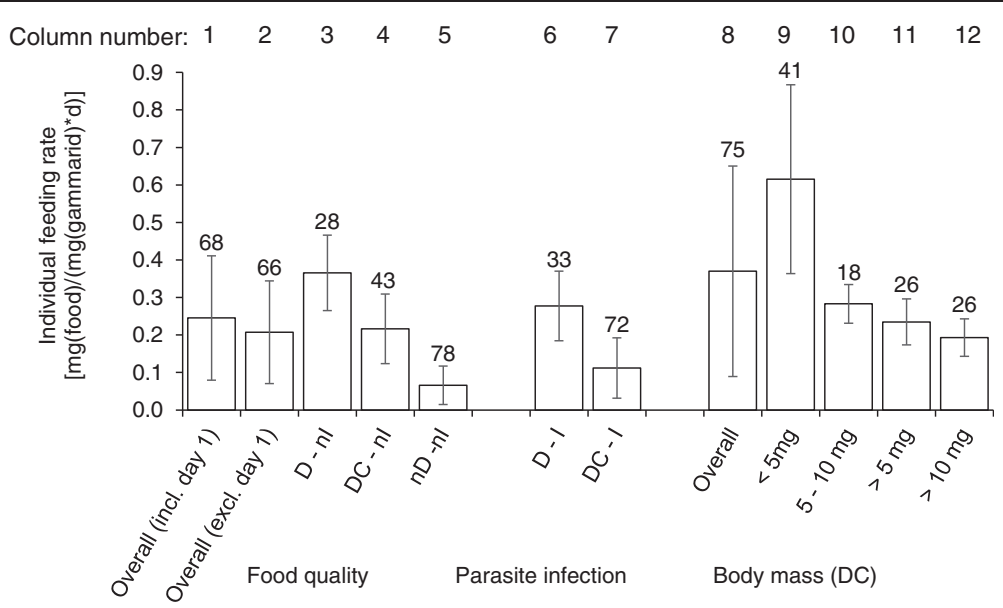

Figure 1 Variation in feeding rate of individual Gammarus pulex. The feeding rate was compared with type of food, presence (I) or absence (nl) of infection with acanthocephalan parasites and body mass. The food source is indicated with DC for horse chestnut leaf discs decomposed with Cladosporium sp., D for leaf discs decomposed in water and nD for non-decomposed leaf discs. The numbers represent the standard deviation as a percentage of the average (i.e. coefficient of variation $\times 100$ ).

twice as much when leaf material was conditioned. Other references show that food preferences for freshwater detritivores are related to the time of inoculation with microorganisms [29,30].

Results demonstrated that standardised food preparation and storage can reduce the variability of the feeding rate of G. pulex in laboratory studies (Figure 1, food quality) which would increase the potential for detecting stressor-related effects ex situ. Within this experiment, a maximal reduction of the variability in feeding rate by $38 \%$ was found when data were distinguished by food quality. The higher the food quality and thus the feeding rate, the lower the variability (Figure 1, food quality).

\section{Parasite infection}

Organisms infected with acanthocephalan parasites showed a lower feeding rate for both food types tested ( $p=0.064$ and $p=0.099$ for food sources DC and D, respectively; power $=0.999$; ANOVA, Holm-Sidak test) (Figure 1). The feeding rate decreased with parasite infection from $0.36 \pm 0.10$ to $0.28 \pm 0.09 \mathrm{mg}$ (food) $/(\mathrm{mg}$ (gammarid $) \times d$ ) when fed with food of source $D$, and from $0.22 \pm 0.09$ to $0.11 \pm 0.08(\mathrm{mg}($ food $) /(\mathrm{mg}($ gammarid $) \times \mathrm{d}))$ by feeding with leaves of source DC (Figure 1, column 4 vs. 7). The results also suggest that the intensity of the influence may have been related to the food source. A reduction in feeding rate caused by parasite infection of $22 \%$ and $50 \%$ was found when fed with the leaf types D and DC, respectively. Excluding infected organisms from laboratory studies reduced the variability of the test results by up to $33 \%$ (Figure 1, column 2 vs. 6).

The results of the present study combined with those of Brown and Pascoe [21] show that a separation of the organisms according to whether or not they are infected with acanthocephalan parasites will reduce the variability of the test results and thus increase the power in a toxicity study to detect any effects caused by a stressor. Standardisation of either parasite infection or food quality might be suitable to reduce the intra-specific variability in the individual feeding rate for successful toxicity studies at a daily resolution. However, it might be advisable to standardise both because significant differences in feeding rate were observed for the tested food sources and infection status.

\section{Body size}

A strong relationship $\left(R^{2}=0.79\right)$ between feeding rate and body mass (given in dry weight $(\mathrm{dw})$ ) was observed for all observation periods. Figure 2 shows the average of the feeding rate as a function of body mass for the whole experimental duration. The feeding rate was consistently higher for smaller organisms.

Figure 3 shows the individual feeding rate over time for three sizes classes of the organism. The feeding rate of each group was compared over time, and it was found that the variability was the greatest and significant for small organisms $(<5 \mathrm{mg})$, whereas for larger organisms, no significant differences in feeding rate over time were observed. Smaller organisms (body mass $<5 \mathrm{mg}$ ) had two to three times higher feeding rates than organisms with a body mass of $>5 \mathrm{mg}$ when calculated over the whole experimental duration (Figure 1). Specification in terms of body mass reduced the variability in feeding rate compared to the mixed groups by $35 \%, 57 \%$ and $49 \%$ for the groups $<5 \mathrm{mg}, 5$ to $10 \mathrm{mg}$ and $>10 \mathrm{mg}$, respectively. 


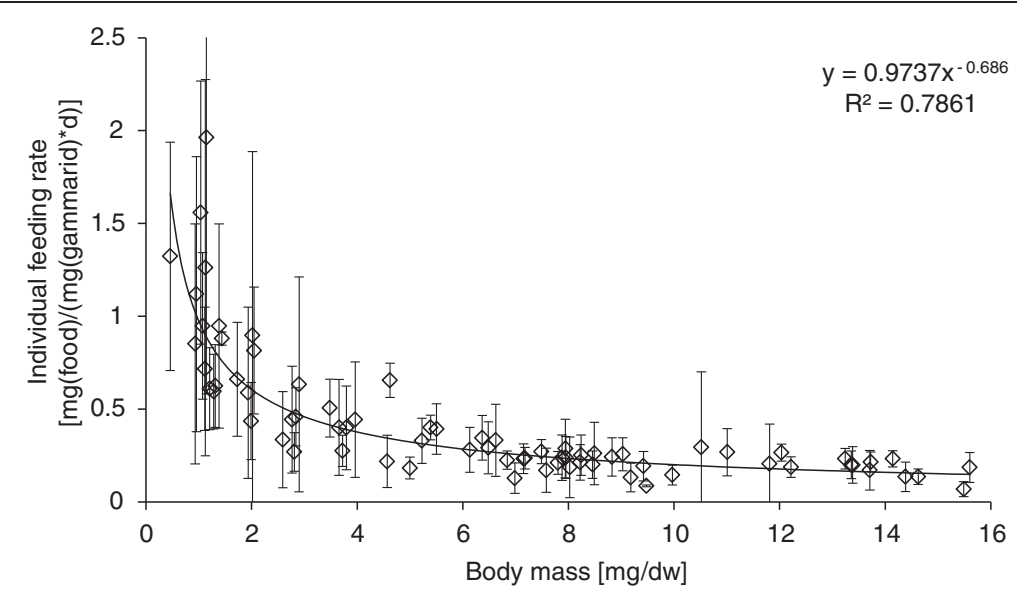

Figure 2 Feeding rate of individual Gammarus pulex as a function of body mass. Average \pm standard deviation for a measurement period of 9 days after changing the food source from non-inoculated (nD) to inoculated food (DC).

When making feeding activity assays with G. pulex, it is advisable to use organisms of a very specific body mass (for example, 2.0 to $2.5 \mathrm{mg}$ ) to reduce the variability of the test results and thus increase the possibility of a successful toxicity study. However, restricting the size range of organisms reduces the relevance of test results for the mixed populations found in the environment. A further option would be to use organisms of a higher body mass because of the decreasing strength of the relationship between feeding rate and body mass with increasing body weight. It was observed that organisms $>5 \mathrm{mg}$ showed a less distinct and not significant fluctuation in feeding rate over time $(p=0.304$ and $p=0.554$ for organisms between 5 and $10 \mathrm{mg}$ and organisms $>10 \mathrm{mg}$, respectively; Kruskal-Wallis test) when compared to smaller organisms (Figure 3); however, this was offset by the disadvantage that the feeding rate was lower than that for smaller organisms (Figure 1). It was observed that the feeding rate of organisms $<5 \mathrm{mg}$ fluctuated greatly over time, yielding significant differences between different observation periods. Such fluctuations must be excluded for toxicity studies. Thus, the results would suggest the use of organisms $>5 \mathrm{mg}$ for toxicity tests. Use of larger organisms reduces uncertainties from weighing, and such organisms can be collected throughout the year [31]. We suggest the use of body length as a measure of an organism's dry weight for practicality in future feeding assays. A correlation between body length and dry weight suitable for organisms between 2 and $16 \mathrm{~mm}$ is given by Graça et al. [28].

\section{Food quality (C-N ratio)}

Large variability in the $\mathrm{C}-\mathrm{N}$ ratio of the food type DC was observed, and this was related to the colour of the

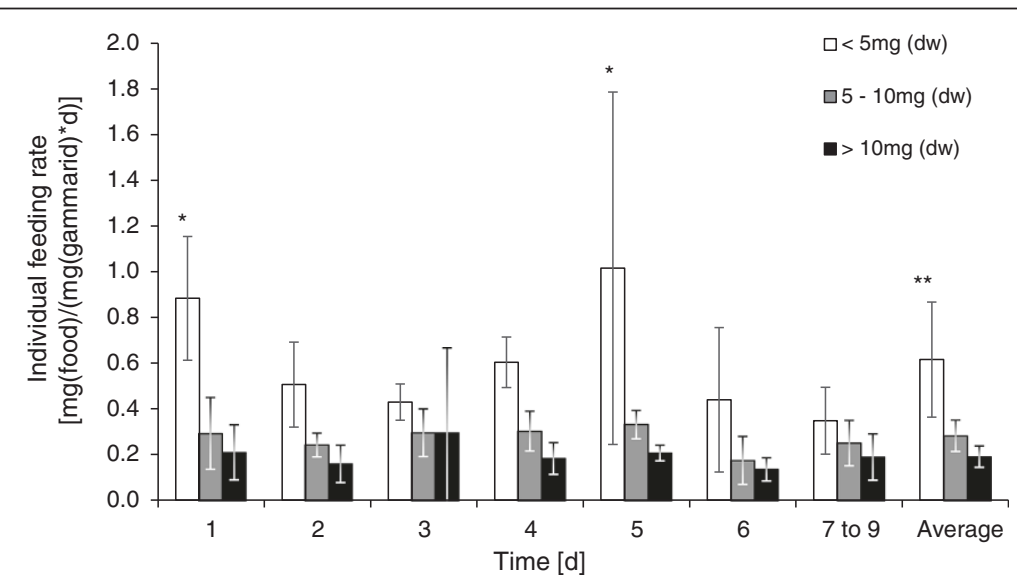

Figure 3 Feeding rate of three different size classes of Gammarus pulex over time. The feeding rates were taken after changing the food source from non-inoculated (nD) to inoculated food (DC). Average values ( $n>18$ for organisms $<5 \mathrm{mg}, n>29$ for organisms of 5 to $10 \mathrm{mg}$, $n>15$ for organisms $<10 \mathrm{mg}$ ). *Significant difference compared to the same group over time $(p<0.05$, Kruskal-Wallis followed by Dunn's test); **significant difference between large and small organisms $(p<0.01)$. 
leaf discs (Figure 4). The relatively large variability in the $\mathrm{C}-\mathrm{N}$ ratio for the food type $\mathrm{DC}$ correlates with a large variability in feeding rate for gammarids fed with this food type. A further separation of the food source within one preparation procedure by nutrient content (here the $\mathrm{C}-\mathrm{N}$ ratio) might reduce the variability of the test results even more than the $38.4 \%$ observed in this study, because the whole set of type DC leaf discs was used. Furthermore, it was observed that $G$. pulex had the smallest $\mathrm{C}-\mathrm{N}$ ratio tested ( $5.55 \pm 0.02)$ followed by Cladosporium sp. (10.32 \pm $0.04)$. These $\mathrm{C}-\mathrm{N}$ ratios are clearly smaller than those of all horse chestnut leaf discs tested (Figure 4). Benthic consumers often contain higher amounts of nitrogen and thus have a lower $\mathrm{C}-\mathrm{N}$ ratio than their food sources [32]. There seem to be exceptions for this observation as the C-N ratio for the food source DS was close to that of the gammarids themselves (Figure 4).

Figure 4 also shows a relationship $\left(R^{2}=0.99\right)$ between the $\mathrm{C}-\mathrm{N}$ ratio of food eaten (leaf discs excluding the veins) and feeding rate. The feeding rate decreased with increasing $\mathrm{C}-\mathrm{N}$ ratio. The decline in the $\mathrm{C}-\mathrm{N}$ ratio with decomposition time of the leaf discs is caused by microbial activity and was also observed for alder and beech leaves in the field [33]. This microbial activity, called conditioning, is an important part of leaf litter processing in aquatic ecosystems which increases the palatability of detritus for shredding organisms [8]. The literature suggests that aquatic shredders prefer food of lower $\mathrm{C}-\mathrm{N}$ ratios because the quality is higher resulting in better nutritional status (original reference in [34]). However, whether food preference really depends on $\mathrm{C}-\mathrm{N}$ ratio is unclear, as information in the literature range from no relationship between those two factors at all [34,35] to a strong relationship [36]. Nutritional composition is a determining factor of food quality [37], and adaptation in feeding activity provides a compensation for sub-optimal composition of available food $[32,38]$.

Under the assumption that G. pulex only eats the amount of food needed to sustain the energy budget and nitrogen is the limiting factor, food consumption would increase as nitrogen content of the food decreased. However, the opposite relationship was observed (Figure 4). An explanation could be that the content of other important nutrients (e.g. phosphorus) might have been decreased during the decomposition by microbial activity and was then limiting. The compensation for this limitation then forced the gammarids to increase their feeding rate. For G. fossarum, another aquatic shredder, it has recently been shown that their growth, which is influenced by feeding, is negatively correlated to the $\mathrm{C}-\mathrm{P}$ ratio of the food source [39]. Our results show that a comparison of feeding activity data generated in experiments using differing leaf species decomposed using different methods might be possible when the $\mathrm{C}-\mathrm{N}$ ratio of the provided food is measured. However, it is advisable to include phosphorus into the testing of nutritional status of food sources; phosphorus is an essential component of food quality alongside carbon and nitrogen [37], and which nutrient is limiting depends on the actual content of the nutrient rather than the ratio.

\section{General discussion}

Decreased intra-specific variability in feeding rate resulted when measurement of feeding rate focused on a sub-group

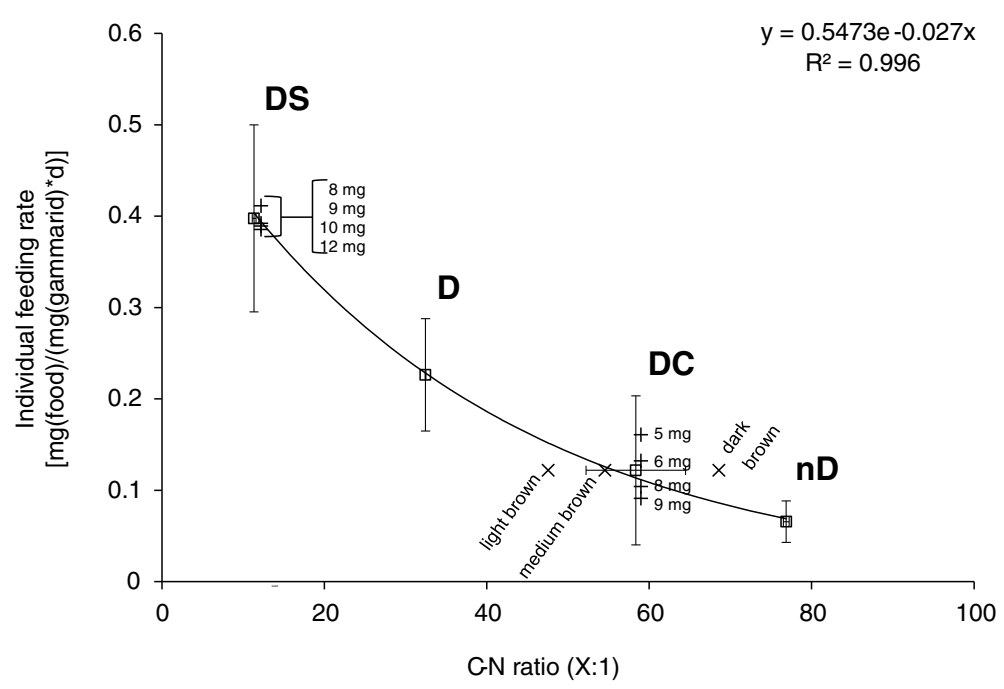

Figure 4 Variation in feeding rate of individual Gammarus pulex with the C-N ratio of food eaten. Average values ( \pm standard deviation) are plotted for the four food sources tested (white square; D, DC, DS and nD), and for the food sources DS and DC, the feeding rate is additionally plotted in dependence of the body weight ( $\mathrm{dw}$ ) of the test organisms (+). The C-N ratio for the food source DC was also determined after classification into three groups of leaf colour $(X)$. 
of gammarids. Selecting organisms of a sub-group in terms of parasite infection and body mass resulted in a reduction in intra-specific variability of up to $50 \%$ and $57 \%$, respectively. Using a food source of particular quality reduced the variability by up to $38 \%$. Acclimation to test conditions only reduced the variability in test results by $1.6 \%$. Certainly, taking into account each of these options to reduce the intraspecific variability for an ex situ feeding assay will maximise the reduction in intra-specific variability, but the result will not be additive.

There are contrasting strategies which can be followed for a feeding assay depending on the objective of the conducted study. The results suggest letting the organisms acclimate to the test conditions for at least 1 day and using organisms that are either all infected or all uninfected. The optimum should be the use of non-infected individuals as the infection tends to reduce feeding rate (present study and [21]), thus reducing the chance of measuring negative impacts due to the tested stressor. Furthermore, it is not known whether both parasites of G. pulex influence feeding in the same manner as here these parasites were not distinguished. The proportion of infection and the intensity of the infection with the parasites will depend on geographical location and season, and may in turn cause differences in impacts on feeding. Therefore, the use of uninfected organisms is recommended. Further research could include the investigation of xenobiotic impacts on feeding of infected organisms as those were shown to be more sensitive than uninfected organisms [21].

The results show that when conducting feeding assays with gammarids, attention has to be given to the selection of the test organisms in terms of their body size. In order to increase the chance of measuring influences of the treatment, the results suggest conducting experiments with organisms of a specific size class. Which size class to use might depend on the length of the planned study. Short-term experiments may be conducted with juvenile organisms of a very particular size because their feeding rate is in general higher than that for adults. Juveniles have been shown to have a higher sensitivity to toxicants [40,41], making this size class a good candidate for toxicity studies. A further reason to select juvenile individuals may be the increased representativeness of the test for the field situation. The density of organisms within the larger size class (adults) in the field is lower than that of smaller organisms [42]. However, as the feeding rate of juveniles fluctuates over time, they may only be suitable for short-term experiments. One may want to increase the number of replicates in such an experiment as the total amount of food consumed by juveniles within a day is rather low which increases the measuring uncertainty. Long-term experiments are particularly important to observe recovery potential following a treatment and for investigation of effects from pulsed exposure. Such experiments should be conducted with adult gammarids to stabilise the control feeding rate over time. A further reason to select adults is their importance for sustainability of the population as these individuals reproduce.

Some attention should be drawn to the food source to be used in a feeding assay. The results suggest using conditioned food prepared in a single batch and the $\mathrm{C}, \mathrm{N}$ and $\mathrm{P}$ content of the food should be measured. Furthermore, more than one leaf disc should be provided per organism in order to reduce the variability of the feeding rate caused by the variability in the food quality. Generally, the longer the leaf material is inoculated with microorganisms, the higher is the feeding rate which, again, increases the chance of measuring negative impacts of the treatment. However, one might want to consider that there is likely a maximum feeding rate which is determined by the food handling time of gammarids. Conducting a feeding assay at such a shredding rate might eliminate the possibility to measure treatment-related increases (i.e. hermetic effects).

\section{Conclusion}

There is no such thing as the perfect method which is valid for all research questions involving feeding assays with gammarids. The presented studies were not undertaken to develop such a method but aimed to enhance the design process to maximise the potential for successful and comparable experiments. We presented a list of factors that naturally have an impact on feeding rates of Gammarus, quantified their impact on the variability in feeding rates, discussed their importance for consideration when planning a feeding assay and suggested some additional measurements alongside the feeding assay to improve data comparison between studies.

\section{Methods}

\section{Test organisms}

We collected G. pulex from a small stream in Bishop Wilton, UK (grid reference: SE7963; latitude 53.985, longitude -0.787 ). The organisms were classified by visual observation immediately after collection into those infected (I) or uninfected (nI) with acanthocephalan parasites. The two parasites Pomphorhynchus laevis and Polymorphous minutes were not distinguished.

The organisms were maintained under continuous ventilation at $13^{\circ} \mathrm{C} \pm 1^{\circ} \mathrm{C}$ and with a photoperiod of $12: 12 \mathrm{~h}$ at 750 to 900 lux in artificial pond water (APW) $(294 \mathrm{mg} / \mathrm{L}$ $\mathrm{CaCl} 2 \cdot 2 \mathrm{H} 2 \mathrm{O}, 123.3 \mathrm{mg} / \mathrm{L} \mathrm{MgSO} 3 \cdot 7 \mathrm{H} 2 \mathrm{O}, 64.8 \mathrm{mg} / \mathrm{L}$ $\mathrm{NaHCO}_{3}$ and $5.8 \mathrm{mg} / \mathrm{L} \mathrm{KCl}$ in deionised water) [13] prior to and throughout experimentation.

\section{Food sources}

Food sources used did not represent the organism's preference of food. The food sources were chosen as a 
compromise combining the reported long-term survival of organisms when fed with this food, standardisation and thus reproducibility of food source production, and practicality of food source handling and storage. Overall we used five different food sources; four were prepared from horse chestnut leafs and one from alder leave. The horse chestnut leaves (Aesculus hippocastanum (L.)) were collected in November and stored after air drying under dry and dark conditions and at room temperature until use $\left(20^{\circ} \mathrm{C} \pm 2^{\circ} \mathrm{C}\right)$. Whole horse chestnut leaves were used as food to maintain the organisms in the laboratory (pre-experimental feeding). These leaves were stored in tap water at room temperature and were conditioned with Cladosporium sp. for at least 3 months prior to use. Horse chestnut leaf discs with a diameter of $1.6 \mathrm{~cm}$ were prepared for use in the experiments. Leaf types used differed in their decomposition state. These were decomposed by inoculation with Cladosporium sp. for 2 weeks (DC), decomposed with Cladosporium sp. for 3 months (D) and non-decomposed $(\mathrm{nD})$. Culture media for the leaf type $\mathrm{DC}$ was enriched water $\left(66.04 \mathrm{mg} / \mathrm{L} \quad\left(\mathrm{NH}_{4}\right)_{2} \mathrm{HPO}_{4}\right.$, $68.05 \mathrm{mg} / \mathrm{L} \quad \mathrm{KH}_{2} \mathrm{PO}_{4}, 87.09 \mathrm{mg} / \mathrm{L} \mathrm{K}_{2} \mathrm{HPO}_{4}, 1.84 \mathrm{mg} / \mathrm{L}$ $\mathrm{CaCl}_{2} \cdot 2 \mathrm{H}_{2} \mathrm{O}$ and $2.54 \mathrm{mg} / \mathrm{L} \mathrm{MgCl}_{2} \cdot 6 \mathrm{H}_{2} \mathrm{O}$ in deionised water) [13] and tap water for the leaf type D. Preparation of the leaf discs DC was by decomposing 150 horse chestnut leaf discs in $300 \mathrm{~mL}$ enriched water inoculated with Cladosporium sp. from a culture on malt extract. The leaf discs $\mathrm{nD}$ were prepared 2 days before the start of the experiment by storing them in tap water in the dark.

Alder (Alnus glutinosa) leaf discs (DS) prepared by inoculation with whole alder leaves previously inoculated in stream water were used as an additional food source. This food source was obtained from the University of Landau, Germany. Detailed information on the preparation of this food source can be found in Zubrod et al. [14]. In short, leaf discs with a diameter of $2.0 \mathrm{~cm}$ were conditioned for 10 days in a nutrient medium. Inoculation of the leaf discs with a river-like microbial community was by addition of alder leaves previously exposed in the Rodenbach, Germany (491330 N, 81020 E). The discs were dried at $60^{\circ} \mathrm{C}$ to constant weight and rewetted in APW 2 days prior to use in an experiment. This procedure was undertaken to guarantee a stable quality of the food sources (food quality within this study is defined as the $\mathrm{C}-\mathrm{N}$ ratio of the food) over time.

\section{Experimental design}

Artificial pond water was replaced every second or third day during all experiments; the oxygen content and $\mathrm{pH}$ in the old and new medium were measured. Mortality and moulting status were recorded daily. The feeding rate of moulting organisms was discounted from analysis during the period when the carapax was changed because the impact of moulting on the feeding rate is so far unknown; previous observations indicate that organisms might stop eating before moulting [43].

\section{Impact of food source and parasite infection}

The first experiment consisted of five treatments, each with three replicates. Each replicate comprised four gammarids (body size 0.6 to $1.2 \mathrm{~mm}$ ), six leaf discs at day one and three leaf discs during subsequent days in $250 \mathrm{~mL}$ APW. Three treatments contained uninfected gammarids and one of the three leaf discs $\mathrm{D}, \mathrm{DC}$ or $\mathrm{nD}$, respectively. Two treatments contained infected gammarids and either the food DC or D. The experiment lasted $96 \mathrm{~h}$. Data for the first feeding period $\left(t_{0 \mathrm{~h}}\right.$ to $\left.t_{24 \mathrm{~h}}\right)$ were excluded from further analysis because of a significant difference in feeding rate relative to subsequent periods. This experiment was conducted at the group level to minimise the variability due to size-dependent differences in the feeding rate.

\section{Measurement of $\mathrm{C}-\mathrm{N}$ ratios}

The carbon and nitrogen content of G. pulex, Cladosporium sp. and all leaf types was measured using a Vario MACRO CN elementar analyser (Elementar Analysensysteme GmbH, Hanau, Germany). Within the food type DC, three groups of leaves were analysed which were visually classified by their colour (light, middle and dark brown). The leaves and veins were analysed separately for calculating the $\mathrm{C}-\mathrm{N}$ ratio of the leaf material consumed, because gammarids do not eat the main veins. Prior to analysis, the samples (duplicates) were dried (96 $\mathrm{h}$ at $105^{\circ} \mathrm{C}$ ), milled and weighed. Sample weight ranged between 6.0 and $28.4 \mathrm{mg}$.

\section{Impact of body mass}

Seventy-five organisms with a body mass between 0.48 and $14.6 \mathrm{mg}$ dw were kept individually in $90 \mathrm{~mL}$ APW and fed daily with three leaf discs of the type DC. Only organisms without visible acanthocephalan parasite infection were used. The experimental period was 9 days.

\section{Individual feeding rate as a function of time for two food sources}

Fifteen organisms with a body mass between 4.64 and $11.96 \mathrm{mg}$ dw were kept individually in $90 \mathrm{~mL}$ APW. All organisms were fed daily with three leaf discs. Ten individuals were fed with the food source DC, and the remaining organisms were fed with leaf discs type DS. Only organisms without visible acanthocephalan parasite infection were used. The feeding rate of each individual was measured on a daily basis throughout the experimental period of 15 days.

\section{Measurement of feeding rate}

To prevent over-estimation of the feeding rate associated with weight loss of the leaf discs caused by leaching and/ 
or decomposition, the measured food at the end of the period $F_{(t)}$ was corrected with a leaching-decomposition factor (ld). This factor was obtained by dividing the weight of the control leaves at the end of the measuring period by the initial weight. The actual amount of food eaten within the observed period $F \mathrm{Ea}_{(t)}(\mathrm{mg} / \mathrm{d})\left(F \mathrm{Ea}_{(t)}=\right.$ $\left.F_{(t-1)}-\left(F_{(t)} / l d\right)\right)$ was then used to calculate the feeding rate $F \mathrm{R}(\mathrm{mg}($ food $) /(\mathrm{mg}($ gammarid $) \times \mathrm{d}))$ at a daily resolution ( $t=$ exactly $24 \mathrm{~h}$ ) by dividing the amount of food actually eaten within the observed period $F \mathrm{Ea}_{(t)}$ by the body mass of the individual $G(\mathrm{mg})\left(F \mathrm{R}=F \mathrm{Ea}_{(t)} / G\right)$. All measurements of weights refer to dry weight $(\mathrm{dw})$.

Body mass of the organisms was measured after the experiment by drying the organisms for at least $24 \mathrm{~h}$ at $90^{\circ} \mathrm{C}$. When the amount of food eaten was observed in wet weight (ww), the dw of the food material was calculated using the experimentally derived linear regression of $\mathrm{dw}=0.186 \times \mathrm{ww}\left(R^{2}=0.865\right.$; data not shown $)$. Weighing was carried out with a Mettler Toledo XS205 Dual Range balance (Columbus, OH, USA) weighing to a precision of $0.01 \mathrm{mg}$.

\section{Statistical analysis}

One- and two-way ANOVAs were performed with the feeding rate $(\mathrm{mg}($ food $) /(\mathrm{mg}($ gammarid $) \times \mathrm{d}))$ of replicates. The Shapiro-Wilk test for normal distribution and the Levene-Mediane test for equal variance were performed prior to ANOVAs. Multiple comparisons of resulting $p$ values were by application of the Holm-Sidak test when normal distribution and equal variance were given. Otherwise, a Kruskal-Wallis test followed by an all pairwise comparison according to Dunn's method was used. Statistical analysis of feeding rates was undertaken with SigmaPlot 11 (Systat Software Inc., London, UK).

\section{Competing interests}

The authors declare that they have no competing interests.

\section{Authors' contributions}

$A A$ and $C B$ planned the experiments which were performed by AA. AA drafted the manuscript. CB reworked the manuscript critically. Both authors read and approved the final manuscript.

\section{Acknowledgements}

This research has been financially supported by the European Union under the 7th Framework Programme (project acronym CREAM, contract number PITN-GA-2009-238148). We would like to thank the two anonymous reviewers and the editor for their comments and support.

Received: 22 April 2014 Accepted: 9 June 2014

Published online: 24 June 2014

\section{References}

1. Sancho E, Villarroel MJ, Andreu E, Ferrando MD: Disturbances in energy metabolism of Daphnia magna after exposure to tebuconazole. Chemosphere 2009, 74:1171-1178.

2. Villarroel MJ, Sancho E, Andreu-Moliner E, Ferrando MD: Biochemical stress response in tetradifon exposed Daphnia magna and its relationship to individual growth and reproduction. Sci Total Environ 2009, 407:5537-5542.
3. Calow P, Sibly RM: A physiological-basis of population processes ecotoxicological implications. Funct Ecol 1990, 4:283-288.

4. Preuss TG, Hammers-Wirtz M, Hommen U, Rubach MN, Ratte HT: Development and validation of an individual based Daphnia magna population model: the influence of crowding on population dynamics. Ecol Model 2009, 220:310-329.

5. Guisande C, Gliwicz ZM: Egg size and clutch size in 2 Daphnia species grown at different food levels. J Plankton Res 1992, 14:997-1007.

6. Porter KG, Gerritsen J, Orcutt JD: The effect of food concentration on swimming patterns, feeding behavior, ingestion, assimilation, and respiration by Daphnia. Limnol Oceanogr 1982, 27:935-949.

7. Agatz A, Cole TA, Preuss TG, Zimmer El, Brown CD: Feeding inhibition explains effects of imidacloprid on the growth, maturation, reproduction and survival of Daphnia magna. Environ Sci Technol 2013, 47:2909-2917.

8. Gessner MO, Chauvet $\mathrm{E}$, Dobson M: A perspective on leaf litter breakdown in streams. Oikos 1999, 85:377-384.

9. Petersen RC, Cummins KW: Leaf processing in a woodland stream. Freshw Biol 1974, 4:343-368

10. Bundschuh M, Zubrod JP, Schulz R: The functional and physiological status of Gammarus fossarum (Crustacea; Amphipoda) exposed to secondary treated wastewater. Environ Pollut 2011, 159:244-249.

11. Crane M, Maltby L: The lethal and sublethal responses of Gammarus pulex to stress: sensitivity and sources of variation in an in situ bioassay. Environ Toxicol Chem 1991, 10:1331-1339.

12. Maltby L, Crane M: Responses of Gammarus pulex (Amphipoda, Crustacea) to metalliferous effluents: identification of toxic components and the importance of interpopulation variation. Environ Pollut 1994, $84: 45-52$.

13. Naylor C, Maltby L, Calow P: Scope for growth in Gammarus pulex, a fresh-water benthic detritivore. Hydrobiologia 1989, 188:517-523.

14. Zubrod JP, Bundschuh M, Schulz R: Effects of subchronic fungicide exposure on the energy processing of Gammarus fossarum (Crustacea; Amphipoda). Ecotoxicol Environ Saf 2010, 73:1674-1680.

15. Bloor MC, Banks CJ: An evaluation of mixed species in-situ and ex-situ feeding assays: the altered response of Asellus aquaticus and Gammarus pulex. Environ Int 2006, 32:22-27.

16. Kunz PY, Kienle C, Gerhardt A: Gammarus spp. in aquatic ecotoxicology and water quality assessment: toward integrated multilevel tests. In Reviews of Environmental Contamination and Toxicology, vol. 205. Edited by Whitacre DM. Springer: New York 2010, 205:1-76.

17. Blockwell SJ, Taylor EJ, Jones I, Pascoe D: The influence of fresh water pollutants and interaction with Asellus aquaticus (L.) on the feeding activity of Gammarus pulex (L.). Arch Environ Contam Toxicol 1998, 34:41-47.

18. Pascoe D, Kedwards TJ, Blockwell SJ, Taylor EJ: Gammarus pulex (L) feeding bioassays - effects of parasitism. Bull Environ Contam Toxicol 1995, 55:629-632

19. Taylor EJ, Maund SJ, Pascoe D: Toxicity of 4 common pollutants to the fresh-water macroinvertebrates Chironomus riparius Meigen (Insecta, Diptera) and Gammarus pulex (L) (Crustacea, Amphipoda). Arch Environ Contam Toxicol 1991, 21:371-376.

20. Taylor EJ, Jones DPW, Maund SJ, Pascoe D: A new method for measuring the feeding activity of Gammarus pulex (L). Chemosphere 1993, 26:1375-1381

21. Brown AF, Pascoe D: Parasitism and host sensitivity to cadmium: an acanthocephalan infection of the fresh-water Amphipod Gammarus pulex. J Appl Ecol 1989, 26:473-487.

22. McCahon CP, Poulton MJ: Lethal and sublethal effects of acid, aluminium and lime on Gammarus pulex during repeated simulated episodes in a welsh stream. Freshw Biol 1991, 25:169-178.

23. Nyman AM, Hintermeister A, Schirmer K, Ashauer R: The insecticide imidacloprid causes mortality of the freshwater amphipod Gammarus pulex by interfering with feeding behavior. Plos One 2013, 8:e62472.

24. Agatz A, Ashauer R, Brown CD: Imidacloprid perturbs feeding of Gammarus pulex at environmentally-relevant concentrations. Environ Toxicol Chem 2013, 33(3):648-653

25. Schellenberg A: Krebstiere oder Crustacea. N: Flohkrebse oder Amphipoda. Gustav Fischer: Jena; 1942.

26. Gledhill T, Sutcliffe DW, Williams WD: British Fresh Water Crustacea Malacos traca: Key with Ecological Notes. Ambleside, UK: Scientific Publication Freshwater Biological Association; 1993. 
27. Dangles O, Guerold F: Influence of shredders in mediating breakdown rates of beech leaves in circumneutral and acidic forest streams. Archiv Fur Hydrobiologie 2001, 151:649-666.

28. Graça MAS, Maltby L, Calow P: Importance of fungi in the diet of Gammarus pulex and Asellus aquaticus. 2: effects on growth, reproduction and physiology. Oecologia 1993, 96:304-309.

29. Bueler CM: Feeding preference of Pteronarcys pictetii (Pelcoptera, Insecta) from a small, acidic, woodland stream. Fla Entomol 1984, 67:393-401.

30. Arsuffi TL, Suberkropp K: Effects of fungal mycelia and enzymatically degraded leaves on feeding and performance of caddisfly Trichoptera larvae. J N Am Benthol Soc 1988, 7:205-211.

31. Demyanov V, Wood SN, Kedwards TJ: Improving ecological impact assessment by statistical data synthesis using process-based models. J R Stat Soc Ser C-Appl Stat 2006, 55:41-62

32. Cross WF, Benstead JP, Frost PC, Thomas SA: Ecological stoichiometry in freshwater benthic systems: recent progress and perspectives. Freshw Biol 2005, 50:1895-1912

33. Groom AP, Hildrew AG: Food quality for detritivores in streams of contrasting pH. J Anim Ecol 1989, 58:863-881.

34. Leberfinger K, Bohman I: Grass, mosses, algae, or leaves? Food preference among shredders from open-canopy streams. Aquat Ecol 2010, 44:195-203.

35. Friberg N, Jacobsen D: Feeding plasticity of 2 detritivore shredders. Freshw Biol 1994, 32:133-142.

36. Irons JG, Oswood MW, Bryant JP: Consumption of leaf detritus by a stream shredder: influence of tree species and nutrient status. Hydrobiologia 1988, 160:53-61.

37. Frost PC, Elser JJ: Growth responses of littoral mayflies to the phosphorus content of their food. Ecol Lett 2002, 5:232-240.

38. Albarino RJ, Balseiro EG: Food quality, larval consumption, and growth of Klapopteryx kuscheli (Plecoptera : Austroperlidae) from a south Andes stream. J Freshw Ecol 2001, 16:517-526.

39. Danger $\mathrm{M}$, Cornut J, Elger $\mathrm{A}$, Chauvet E: Effects of burial on leaf litter quality, microbial conditioning and palatability to three shredder taxa. Freshw Biol 2012, 57:1017-1030.

40. Blockwell SJ, Pascoe D, Taylor EJ: Effects of lindane on the growth of the freshwater amphipod Gammarus pulex (L). Chemosphere 1996, 32:1795-1803.

41. Adam O, Degiorgi F, Crini G, Badot P-M: High sensitivity of Gammarus sp. juveniles to deltamethrin: outcomes for risk assessment. Ecotoxicol Environ Saf 2010, 73:1402-1407.

42. Allan JD, Malmqvist B: Diel activity of Gammarus pulex (Crustacea) in a south Swedish stream: comparison of drift catches vs baited traps. Hydrobiologia 1989, 179:73-80.

43. Hargeby A, Petersen RC: Effects of low $\mathrm{pH}$ and humus on the survivorship, growth and feeding of Gammarus pulex (L) (Amphipoda). Freshw Biol 1988, 19:235-247.

doi:10.1186/s12302-014-0015-4

Cite this article as: Agatz and Brown: Variability in feeding of Gammarus pulex: moving towards a more standardised feeding assay.

Environmental Sciences Europe $2014: 15$.

\section{Submit your manuscript to a SpringerOpen ${ }^{\circ}$ journal and benefit from:}

- Convenient online submission

- Rigorous peer review

- Immediate publication on acceptance

- Open access: articles freely available online

- High visibility within the field

- Retaining the copyright to your article 